\title{
The Wisdom of Culture
}

\section{A Study on the Relationship between Traditional Poetry, Calligraphy and Painting of China and Interior Furnishing}

\author{
Ying Cao \\ School of Mechanical Science \& Engineering of HUST \\ Wuhan, China \\ e-mail: 150110363@qq.com
}

\author{
Fang Jiang \\ The school of arts \\ Hubei University of Education
}

\begin{abstract}
Traditional art and culture are the precious wealth of all humanity. This paper analyzes the relationship between traditional poetry, calligraphy and painting of China and interior furnishing through the interconnection between art and culture. The author hopes to explore further and wider channels that convey the greatness of culture. Interior furnishing is a subject closely related to human life. Appreciating life from furnishings and understanding culture in life are the purpose of this paper; which requires people to interpret them together.
\end{abstract}

Keywords-traditional culture; poetry; calligraphy and painting; spatial awareness; interior furnishing; and ideas of furnishing

\section{INTRODUCTION}

Traditional poetry, calligraphy and painting are the symbols of Chinese traditional art and culture from which we can feel a lot of consciousness. They reflect people's way of thinking, as well as people's way of life. Ideas conveyed by poetry, calligraphy and painting influence modern people's furnishing ideas and promote the development and modernization of the ideas.

\section{CHINESE POETRY, CALLIGRAPHY AND PAINTING REFLECT CHINESE SPATIAL AWARENESS}

"Everything is cyclical." It is the Chinese spatial awareness reflected in "The Book of Changes". The spatial awareness is to investigate all of the space with heart, to make nature rhythmic through romantic charm. It differs from all external views of the universe, which can be expressed in a poem - "everything listens to itself and the space is always solitary".

There is a poem that said, "A poem is excellent if it can be embodied in a painting; a painting is legendary if it can blend a poem". Actually, there are many successful examples of poems in painting and paintings in poem "Fig.1" \& "Fig.2". This paper does not aim to study the purpose of poems and paintings themselves, but to extract the spatial awareness interconnected by poetry and painting. One of Du Fu's poems said, "The secret water bypasses the flower trails; stars in spring reflect on the thatched cottages." A Wang Wei poem said, "People used to deal on boats. The wood roads are on the top of the mountain." These classical sentences all reflect a kind of flat painting conception. Chinese landscape painters convey the same ideas on their drawing papers. It is just the "absorbing everything" spatial attitude of Chinese people that makes Chinese painting avoid using the perspective method until now. However, it is not that Chinese spatial perspective is narrow and limited. Lao $\mathrm{Zi}$ said that "you could know things happened without going out and you can understand great theories without reading books". It can be seen that Chinese have ascended space to a philosophical level of "seeing from macro the micro things and grasping the whole from the local". At this level, it is not just an objective presentation reflected by poetry, calligraphy and painting, but a profound art and philosophy realm within the unity of time and space. The painting world has a saying that, "If the painting is life-like, mountains are alive. If the poem is ingenious, clouds are willing to stay." An excellent landscape painting accompanied by wonderful poems can not only brighten the painting but also entrust the feelings of poets and painters, which is the spiritual realm pursued by Chinese people. It can be seen that "Chinese people are able to see un-limitedness from limitedness and come back to limitedness from un-limitedness. His ideal interest is not going out without coming back, but in a cycle"1. Various kinds of arts are affected and infused with each other. Therefore, the active spatial ideas reflected in Chinese poetry, calligraphy and painting are naturally permeated into the initial field of furnishing art. Rhythm, rhyme, order, and harmony play an important role in this field, because it represents the tension of life pursued by generations after generations.

From Zong Baihua. Spatial awareness reflected in the Chinese poetry, calligraphy and painting. Chinese Architectural Aesthetics Literary. P286. 

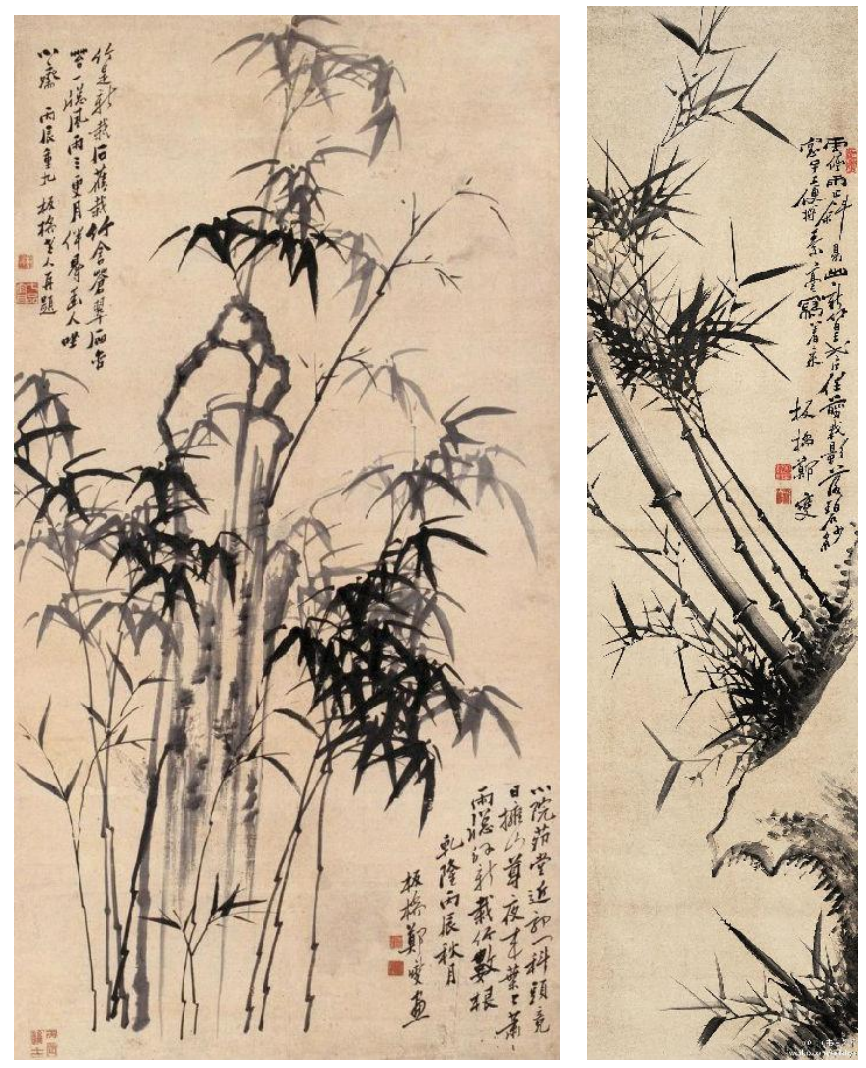

Fig. 1. Poem painting of Zheng Banqiao

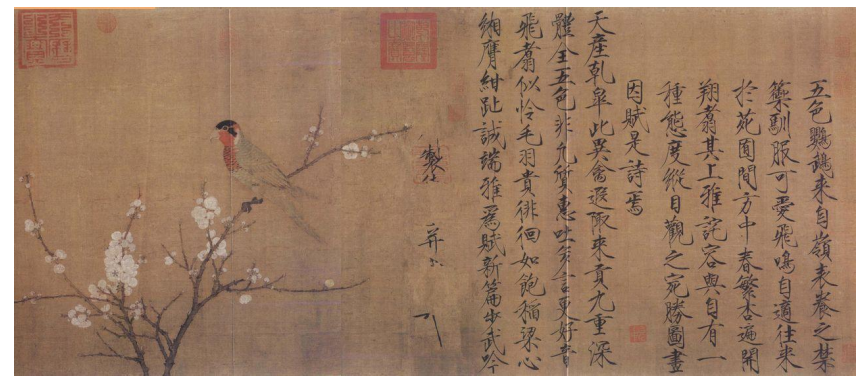

Fig. 2. Song paintings

\section{SPATIAL AWARENESS DETERMINES THE WAY OF INTERIOR FURNISHING}

As with architecture, furnishing must possess demands both on material and spirit. The material function of furnishing, which is its practicability value, is relatively easy to accomplish. Therefore, the spiritual function of furnishing, which is people's psychological demand, rises to the important status. To carry out interior furnishing, firstly it is necessary to consider what kind of space it is in. Furnishing is the full part of space. It exists by the accomplishment of the empty part. Thus the awareness of emptiness determines the direction of the full and spatial form created in full by giving people feedback of different psychological feelings "Fig. 3". It is this kind of spirit that passes traditional poetry, calligraphy and painting onto people. It is a culture, a national culture, which can express feelings and cultivate taste. This kind of culture does not stay on the surface but pursues artistic conception. It is not on the basis of realism, but the pursuit of similarity in spirit. So in the field of interior furnishing, the spatial awareness reflected by poetry, calligraphy and painting should greater reflect inherent things.

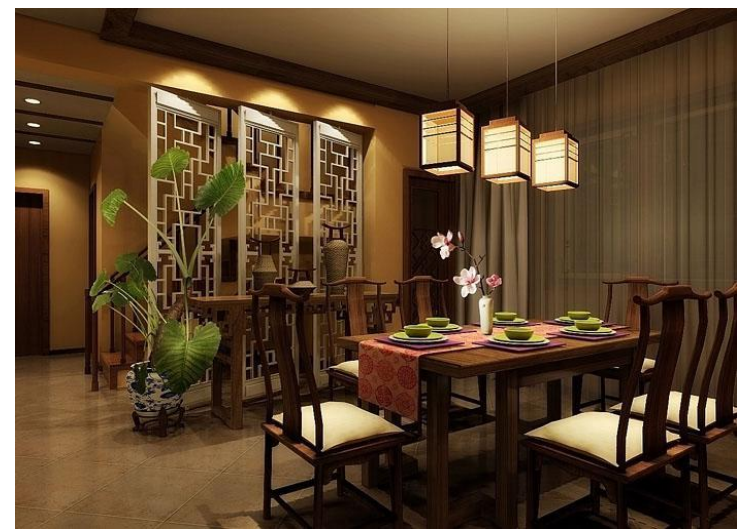

Fig. 3. Examples of space

Of course, it is not to say that all Chinese people choose the same way of furnishing in living rooms because of the influence from traditional culture. Men's education degrees are different, as are the feelings of life. What is more, they are affected by economic conditions and social systems. This inevitably leads to differences in lifestyles. In old times, there were many poor scholars with ideas. Just as there were definitely some calligraphies and paintings hanging on the walls of their houses, there were books on the shelves. On the surface, poetry, calligraphy and painting naturally became furnishings. However, in rich families it was no wonder to see framed valuable calligraphies and hardcover books - although they did not read a lot of books. For them, calligraphy and painting have more furnishing attributes and showing off psychology. But it is inappropriate to deny the values of the calligraphy and painting themselves. Poetry, calligraphy and painting will not change their cultural connotation because of no frames. That is why they were able to become the essence of traditional culture. Therefore, poetry, calligraphy and painting conveyed overall spatial awareness to people; but evolved into a variety of expressions due to different people's understanding. So interior designers should master a kind of aesthetic characteristics, which are on the basis of reality, encouraging and able to convey people's true feelings. "It is not a shallow optimism, nor indifferent wondering, but never-ending progress. The beautiful flame acquired in the process of progress can cultivate people".

There are different degrees and features of indoor environments, different characteristics in expressing cultural connotation. To put it simply, what some people comprehend from poetry, calligraphy and painting is not only a virtual spatial flavor. They focus on absorbing antique and euphemistical traditional color modes. Therefore, the indoor furnishing style expressed may be not be shaped from the 
view of space. Instead, color is chosen as the beginning of expression. Display space is gradually formed according to the deficiency and excess, as well as the movement and stillness of color. For example, the most popular and common way to display calligraphy and paintings is to hang them upon walls. However, since the old times, people have begun to learn innovation and change. Calligraphy and painting can also appear on walls and doors "Fig. 4", on screen partitions "Fig.5" \& "Fig.6", and even on ceilings and pillars. These ways of displaying calligraphy and painting in a space through many channels are furnishing the ideas as poetic flavor, painting flavor and architecture flavor. ${ }^{2}$ Surely it can bring convenience and pleasure to people's life. Of course, the idea of furnishings is not fixed in the furnishing style. If a designer has a deep understanding of Chinese traditional culture and has a profound cultural background, his work could also reflect the traditional verve although he does not purposely seek for traditional culture characteristics, even in the pursuit of the modern cultural style of the design. It reflects the link between the past and today. This is an inheritance relationship.

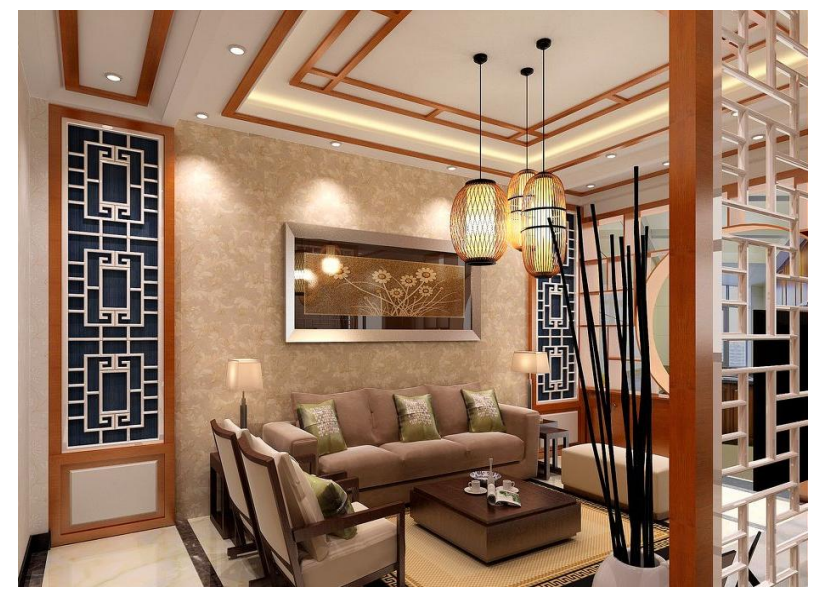

Fig. 4. Paintings hanging on the wall

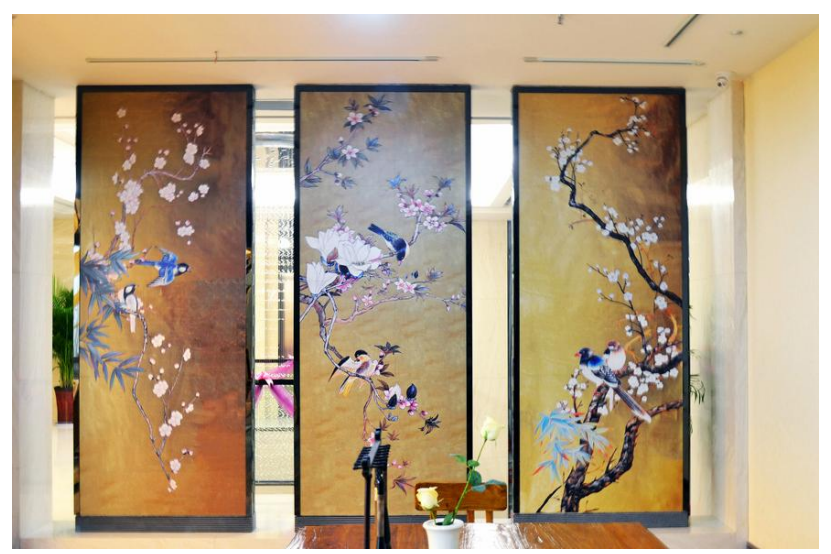

Fig. 5. Screen

\footnotetext{
${ }^{2}$ From Liang Sicheng, Lin Huiyin. Miscelanea of Rual Architecture. Chinese Architectural Aesthetics Literary. P210.
}

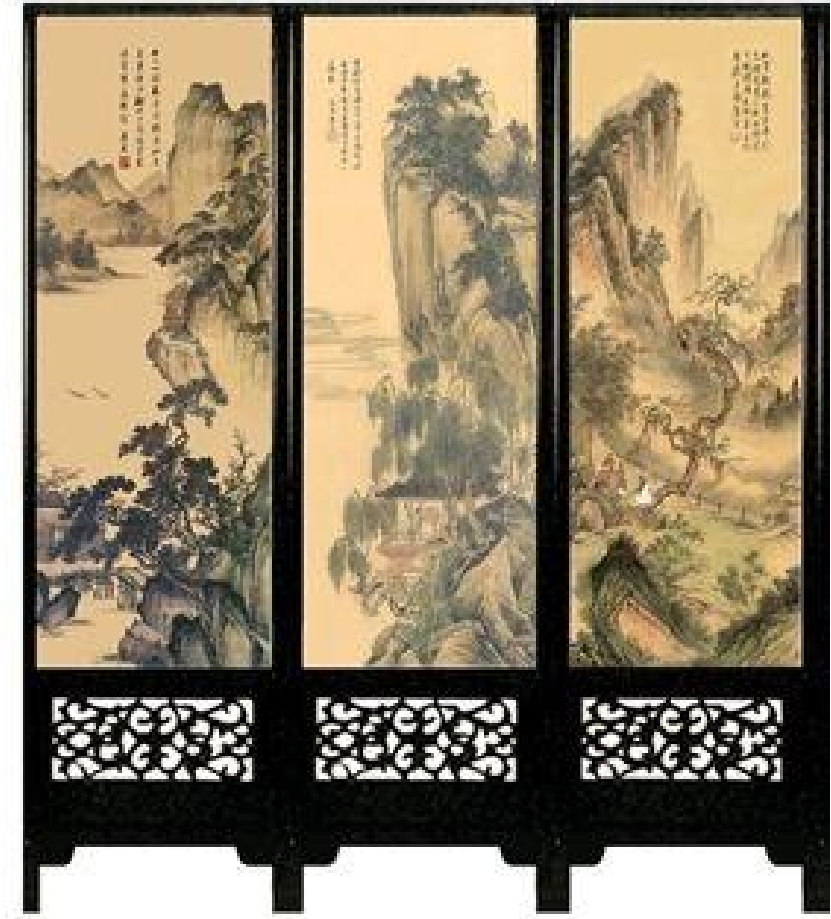

Fig. 6. Screen

\section{THE STYLE OF THE INTERIOR FURNISHING HIGHLIGHTS THE TASTE OF LIFE}

The Changes of Books, Leather hexagrams has already summarized the philosophical statement "in accord with days and in demand of people". The integration of nature and the Chinese people actually also includes interaction between nature and human. They believe that human's utmost sincerity is able to control nature. That is to say that Chinese people respect and worship nature, but they do not deem that nature is perfect. Moreover, it is consistent with the saying that "believing everything the books say is as mindless as believing in nothing". Humans can make up the deficiency of nature. This concept is very optimistic.

Interior furnishing actually includes a lot of contents. It is not a simple accumulation. There are still some changes in function even if there is not change in space. The idea is key. Different spatial styles formed by different interior display modes can actually reflect different tastes of life. Compared with an indoor environment, articles displayed give the indoor space spirit and life.

Let us come back to the surface image of poetry, calligraphy and painting. Calligraphy and painting are usually classified as decorative furnishings. To some extent, modern interior furnishing is a carrier of culture. It conveys the life philosophy of users. When using artistic quality items to decorate space, calligraphy and painting are absolutely the best choices - they only need a small space however have a strong appreciation quality. Hanging it in houses or putting in on tables or walls can build different atmospheres due to different subjects and content, and make the room show 
different temperament. Traditional Chinese calligraphy and painting emphasizes the atmosphere in order to increase cultural appeal for rooms. Although modern art's understanding of life has been raised to an unprecedented height, a good calligraphy and painting will become the burden of space if it is not in harmony with the space. Therefore, the appropriate existence of calligraphy and painting in space is the most critical.

Displaying books is different from calligraphy and painting. It belongs to a kind of indoor functional display. The richer a persons life, the more attention will be paid to the appropriate display of books. Generally speaking, books are put on bookshelves. Only a few books people often read are displayed freely. The traditional bookcase is generally fairly organized, but a little bit stuffy. Actually, we can choose a case to suit the space and atmosphere according to actual indoor demand "Fig. 7". Size, color and package can all help to display books in classification. It can also help for the bookshelf to have a reasonable height, space and division. Sorting books orderly, in addition with books standing or crossing, can produce the flavor of furnishing. Small ornaments on bookshelves foil each other with books. The adornment effect is good. Plants, antiques, and small decorations are good partners for books display. Their interspersed layout can add interest to a bookshelf and reflect the host's taste of life. A little bit of sorting out of scattered books could also achieve an illuminative effect.

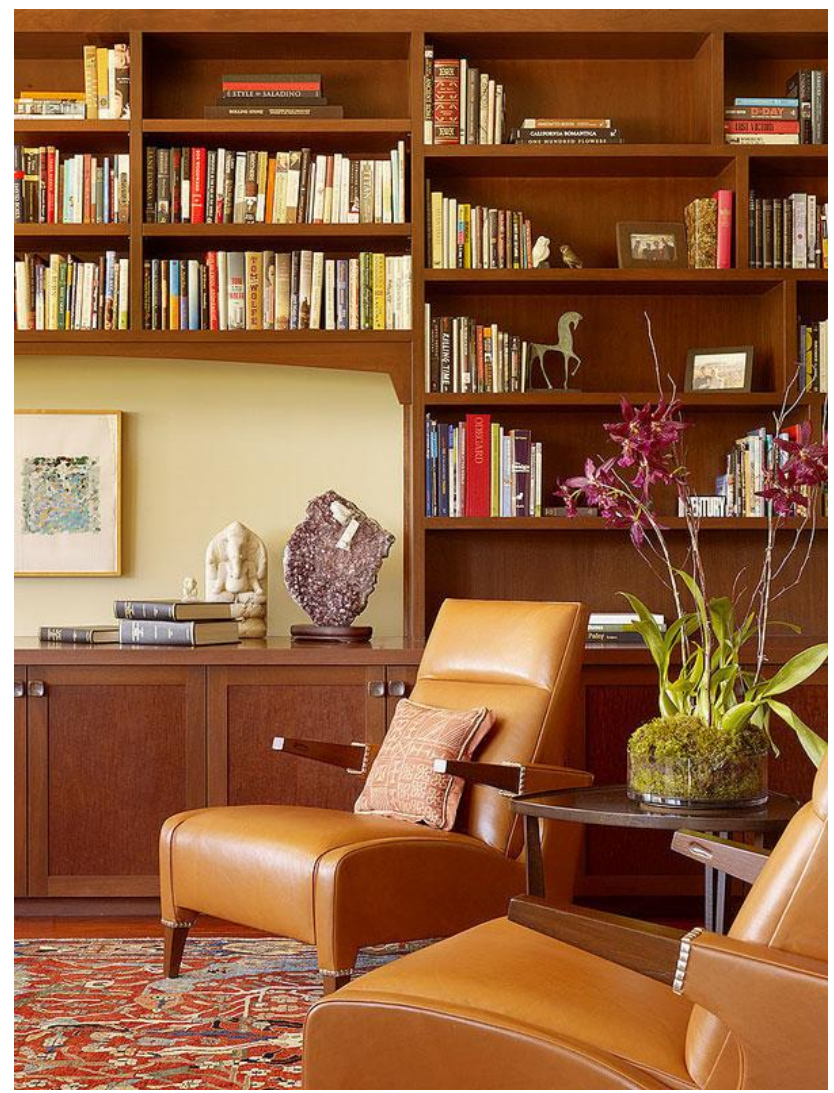

Fig. 7. Bookcase display

\section{THE TASTE OF LIFE REFLECTS THE WISDOM OF CULTURE.}

The Chinese nation has its own cultural tradition and artistic style, which is shown special attention in the display of poetry, calligraphy and painting. The display of elegant style and a certain cultural connotation has already surpassed the aesthetic definition of itself. They already attach spiritual values to indoor space. For example, the atmosphere built by poetry, calligraphy and painting can make people yearn for fun here and further stimulate people's desire for knowledge. This kind of display culture can not only reflect people's characters and hobbies, taste and accomplishment, but is also one of the ways in which people achieve self-expression, which is very wise.

So specifically to art and culture, how do they convey wisdom? For example, Chinese painting is traditional art and culture. Taking Zhang Lianggao's "seven beauties of Chinese painting" to analyze his pursuit of beauty is to stress group, space, color, insubstantial scene, level, echo and harmony. The seven beauties reflect the relationship between the purpose of architecture and paintings, and are in consistent ideas of furnishing represented in the poetry, calligraphy and painting. That is to say, traditional culture is profound, but they also achieve mastery through a comprehensive study. Culture guides life and develops through life.

Humans' artistic and cultural heritages are enough for everyone to enjoy in the limited life. In the more advanced information age in the future, people can live in their favorite previous era simply based on the spirit. No one can predict what form art will take in the future. But no sound society hopes that their existence does not need culture. Thus, art and culture will continue to play an indelible role on people's lives in the generations to come. And this is just its wisdom.

\section{CONCLUSION}

The research scope of furnishing and artistic design is quite extensive. This paper only chooses the cultural aspect to carry out analysis with traditional poetry, calligraphy and painting as the breakthrough points. The saying goes that "The green bamboo leaves are unwilling to turn yellow. Branches can suffer and resist the severe frost. Spring breeze can arouse everything. Bamboo shoots are busy coming out from the earth". The wisdom of traditional culture is like a spring breeze; it can arouse everything. When the spring breeze blows over, the achievements of furnishing art will come out.

\section{REFERENCES}

[1] Chen Zhenping. Art of Furnishings, Zhejiang Academy of Arts Press.

[2] Wang Mingxian, Dai Zhizhong. Chinese Architectural Aesthetics Literary. Tianjing Science and Technology Press.

[3] Zhang Lianggao. Seven Beauties of Artisian. China Architecture \& Building Press. 